\title{
Human bocavirus (HBov1 and HBov2) in Children with Acute Gastroenteritis from North India
}

\section{Kapoor R and Dhole TN*}

Department of Microbiology, Sanjay Gandhi Post Graduate Institute of Medical Sciences, Lucknow, India

*Corresponding author: Dr. Tapan N Dhole (MD), Professor and Head Department of Microbiology, Sanjay Gandhi Post Graduate Institute of Medical Sciences, Lucknow, Uttar Pradesh, India, Tel: +91-522-2494263; E-mail: tndhole@gmail.com

Received date: July 21, 2016; Accepted date: August 23, 2016; Published date: August 30, 2016

Copyright: ( 2016 Kapoor R, et al. This is an open-access article distributed under the terms of the Creative Commons Attribution License, which permits unrestricted use, distribution, and reproduction in any medium, provided the original author and source are credited.

\begin{abstract}
Objective: Human bocavirus is responsible for respiratory as well as in gastroenteritis illness in several countries including India. This study was aimed to characterize the Human bocavirus in North Indian children suffering with acute gastroenteritis.
\end{abstract}

Methods: A total of 234 diarrheal stool specimens from the children under the age of 15 years were collected and screened for the presence of Human bocavirus by polymerase chain reaction targeting NS1 and VP1/2 gene followed by sequencing and phylogenetic analysis. Student's t test was performed for statistical analysis of quantitative clinical data.

Results: Total 7 (3\%) samples were positive for Human bocavirus including bocavirus1 ( $\mathrm{n}=4,1.7 \%)$ and bocavirus2 $(n=3,1.3 \%)$. Median age of bocavirus positive children was 8 months (mean \pm SD; $24.14 \pm 27.58$ months). Age, duration of diarrhea and episodes of diarrhea were the significant clinical factors ( $p$ values 0.0486 , 0.0015 and 0.0282 respectively) for bocavirus infection. Interestingly, male were dominated than females (6:1). Phylogenetic analysis showed that Indian bocavirus sequence has similarity with China strains.

Conclusion: Detection of two bocavirus species in gastroenteritis from North India supports global presence of bocavirus. The outcome of the study facilitates more detailed studies of bocavirus infection, its prevalence and disease association in Indian population.

Keywords: Diarrhea; Viral gastroenteritis; Bocavirus; Phylogenetic analysis; North India

\section{Introduction}

Acute Gastroenteritis (AGE) is a major cause of morbidity and mortality in children worldwide. Several viruses are associated with gastroenteritis, including rotavirus, adenovirus, astrovirus and calicivirus etc. [1-3]. However, about $35-50 \%$ of non-bacterial acute Gastroenteritis is un-identifiable due to unrecognized etiologies [4,5]. Parvovirus is known to cause gastroenteritis in numerous animal species including dogs, cats and hamsters. Several different species and genotypes of Parvovirus infect humans, including the well characterized Parvovirus B19, PARV4 [6], PARV5 [7] and recently identified bocavirus.

Human bocavirus (HBoV), a well-known parvovirus was identified a decade ago in respiratory samples [8] as well as in stool samples [9]. Since then its global presence has been reported in patients with or without gastroenteritis. The Human bocavirus (HBoV) genome consists of approximately $5.2 \mathrm{~kb}$ nucleotides in length and contains three open-reading frames (ORF) encoding two non-structural proteins (NS1 and NP1) and two capsid proteins (VP1 and VP2) [6] Based on the Phylogenetic analysis, there are four $\mathrm{HBoV}$ species: $\mathrm{HBoV} 1, \mathrm{HBoV} 2, \mathrm{HBoV} 3$ and $\mathrm{HBoV} 4$. HBoV1 was first discovered in respiratory samples [8]. While $\mathrm{HBoV} 2, \mathrm{HBoV} 3$ and $\mathrm{HBoV} 4$ were identified in fecal samples of children who had gastroenteritis with or without symptoms of respiratory infection [9-11]. Very few data are available about presence of bocavirus from India but recently some studies from Delhi and Pune confirmed the association of $\mathrm{HBoV}$ in respiratory [12] as well as in gastroenteritis samples [13]. From North India bocavirus has not been reported in association with gastroenteritis, so this study was aimed to define the presence, prevalence and clinical association of bocavirus in North Indian pediatric patients with AGE.

\section{Materials and Methods}

\section{Patients and clinical samples}

Stool specimens of 234 children under the age of 15 years, presenting symptoms of AGE were collected during July 2012 to June 2013 from Sanjay Gandhi Post Graduate Institute of Medical Sciences, Lucknow, India. This study was approved by Institutional ethics committee. Only the patients with informed written consent from parents/guardians were enrolled in this study. Selection of patients based on the criteria of the World Health Organization (WHO) definition of gastroenteritis having three or more loose stools or any vomiting in 24 hrs. Patients having bloody diarrhea or diarrhea with more than 14 days were excluded. Since the bocavirus has a wellknown presence in respiratory diseases, patients having respiratory and lung related diseases were excluded to define the association of bocavirus with gastroenteritis. 
Citation: Kapoor R, Dhole TN (2016) Human bocavirus (HBov1 and HBov2) in Children with Acute Gastroenteritis from North India. J Antimicro

\section{Sample processing}

Sample processing was done by making $10 \%$ stool suspension in phosphate buffer saline, followed by vortexing at mechanical shaker for $20 \mathrm{~min}$ and centrifugation at $3000 \mathrm{~g}$ for $20 \mathrm{~min}$ to pellet particulate matter, the supernatant then passed through a $0.45 \mu \mathrm{m}$ filter. The filtrate was transferred in cryovials and stored at $-20^{\circ} \mathrm{C}$ until use.

\section{PCR and sequencing}

Total nucleic acids were extracted from $200 \mu \mathrm{L}$ of stool filtrate using QiAamp DNA mini extraction kit (QIAGEN, Inc., Valencia, CA, USA) according to the manufacturer's instructions. The extracted DNA was stored at $-70^{\circ} \mathrm{C}$ until use.

HBoV nucleic acids were detected using the previously described PCR primers and conditions for pan-Bocavirus $N S$ gene $(\approx 290 \mathrm{bp})$ and VP1/2 PCR ( $\approx 570$ bp) $[14,11]$ (Table 1$)$.

\begin{tabular}{|c|c|c|c|c|}
\hline Direction & $\begin{array}{l}\text { Primer } \\
\text { Name }\end{array}$ & Region & Sequence $\left(5^{\prime}-3^{\prime}\right)$ & $\begin{array}{l}\text { Refere } \\
\text { nce }\end{array}$ \\
\hline Forward & panBOVF1 & $\begin{array}{l}\text { NS1 } \\
\text { bp) }\end{array}$ & $\begin{array}{l}\text { 5'- } \\
\text { TAATGCAYCARGAYTGG } \\
\text { GT } \\
\text { IGANCC -3' }\end{array}$ & [13] \\
\hline Reverse & panBOVR1 & & $\begin{array}{l}\text { 5'- } \\
\text { GTACAGTCRTAYTCRTTR } \\
\text { AA } \\
\text { RCACCA-3' }\end{array}$ & \\
\hline Forward & panBOVF2 & & $\begin{array}{l}5^{\prime}- \\
\text { GCAYCARGAYTGGGTIGA } \\
\mathrm{N} \\
\text { CCWGC-3' }\end{array}$ & \\
\hline Forward & AK-VP-F1 & $\begin{array}{l}\text { VP1/2 (570 } \\
\text { bp) }\end{array}$ & $\begin{array}{l}5^{\prime}- \\
\text { CGCCGTGGCTCCTGCTC } \\
\text { T-3' }\end{array}$ & {$[14]$} \\
\hline Reverse & AK-VP-R1 & & $\begin{array}{l}\text { 5'- } \\
\text { TGTTCGCCATCACAAAA } \\
\text { GA } \\
\text { TGTG-3' }\end{array}$ & \\
\hline Forward & AK-VP-F2 & & $\begin{array}{l}5^{\prime}- \\
\text { GGCTCCTGCTCTAGGAA } \\
\text { AT } \\
\text { AAAGAG-3' }\end{array}$ & \\
\hline Reverse & AK-VP-R2 & & $\begin{array}{l}\text { 5'- } \\
\text { CCTGCTGTTAGGTCGTT } \\
\text { GTT } \\
\text { GTATGT-3' }\end{array}$ & \\
\hline
\end{tabular}

Table 1: Primer sets used in this study for the detection of Human Bocavirus in gastroenteritis samples.

PCR reactions include $2.5 \mathrm{U}$ of Taq DNA polymerase (New England Biolabs, NEB) in 1.1 Thermopol reaction buffer with $\mathrm{MgCl}(2.0$ $\mathrm{mmol} / \mathrm{L}$ ), $50 \mathrm{pmol} / \mathrm{L}$ (each) of forward and reverse primers and $5 \mu \mathrm{L}$ of nucleic acids (for the first round) and $0.5 \mu \mathrm{L}$ of the first-round PCR product (for the second round) as a template in a $50 \mu \mathrm{L}$ total volume. The products were visualized following electrophoresis on $2 \%$ agarose gel. PCR products, showing positive bands of approximately $290 \mathrm{bp}$, corresponding to the highly conserved amplified $N S$ gene fragment and $570 \mathrm{bp}$ band for $V P 1 / 2$ gene (Figure 1 and Figure 2).

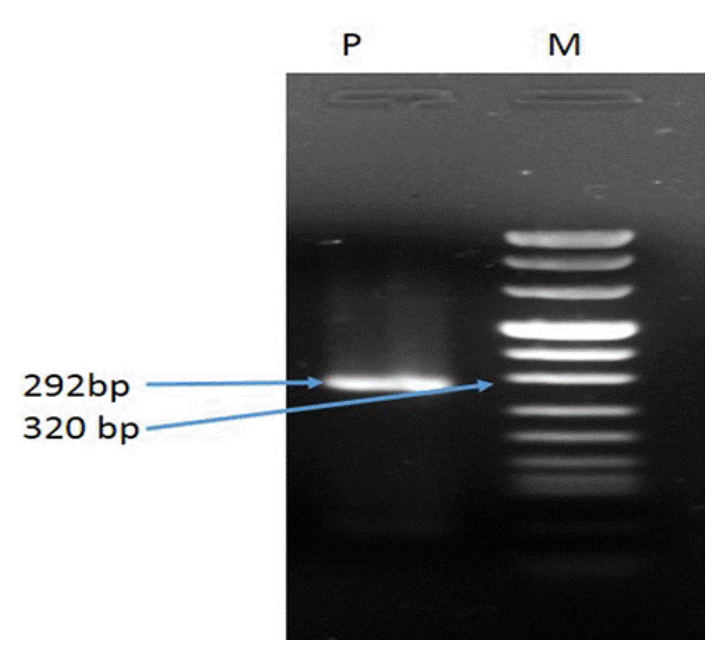

Figure 1: Agarose gel Image for bocavirus Positive for NS1 gene.

Agarose gel electrophoresis image showing positive bands of bocavirus on $2 \%$ agarose gel. Lane $\mathrm{M}$ is a DNA molecular weight marker VIII (19 bp to $1114 \mathrm{bp}$ ). Lane P is positive band of bocavirus NS1 gene (292 bp).

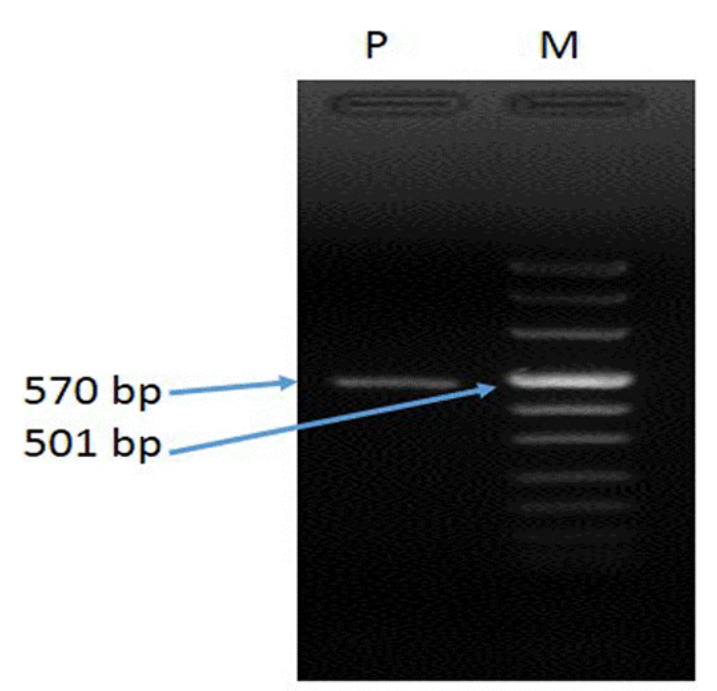

Figure 2: Agarose gel Image for bocavirus Positive for $V P 1$ gene.

Agarose gel electrophoresis image showing positive bands of bocavirus on $2 \%$ agarose gel . Lane $\mathrm{M}$ is a DNA molecular weight marker VIII (19 bp to $1114 \mathrm{bp}$ ). Lane $\mathrm{P}$ is positive band of bocavirus $V P 1$ gene (570 bp).

All the $\mathrm{HBoV}$ positive second round PCR products were treated with Exo-Sap-IT (USB) before direct sequencing. Purified PCR products were sequenced for both forward and reverse primers by $\mathrm{ABI}$ Sequencer (scanner v.1.0, model no 3130 l). Sequencing was done for both $N S 1$ and $V P 1 / 2$ genes to define the genetic makeup of North Indian bocavirus. 
Sequence data obtained using forward and reverse primers was aligned and edited manually using BioEdit program. Sequences were first analyzed using NCBI Blast N (http:// www.ncbi.nlm.nih.gov/ BLAST) analysis to find $\mathrm{HBoV}$ variants that were genetically most related to $\mathrm{HBoV}$ isolates identified in this study. Phylogenetic analysis of NS1 and VP1 sequences identified in this study with best matched NCBI blast search sequences and GenBank reference sequences was performed by Mega 5.05 using maximum likelihood method and Tamura-Nei model with 1000 replicate bootstrapping of the tree to obtain confidence in clade clustering.

Statistical analysis of all the clinical data including age, duration of diarrhea and vomiting in days, episodes of diarrhea and vomiting in 24 hours were performed using student's $t$ test by GraphPadInStat 3 .

\section{Results}

\section{Prevalence of Human bocavirus}

Out of 234 samples $\mathrm{HBoV}$ were present in 7 (3\%) of which 4 were HBoV1 (1.7\%) and 3 (1.3\%) were HBoV2.

\section{Demographic and clinical profiling}

Of the $7 \mathrm{HBoV}$ infected children 6 were male and one was female. All the $\mathrm{HBoV}$ infected patients were under the age of 6 years. The median age of $\mathrm{HBoV}$ positive cases was 8 months. No significant seasonal distribution of bocavirus has been observed in the studied period. Presence of bocavirus was almost throughout the year though its positivity was higher in the month of January $n=2 ; 29 \%$ and March $\mathrm{n}=2 ; 29 \%)$ while $1(14 \%)$ sample is positive in July, September and November individually (Figure 3).

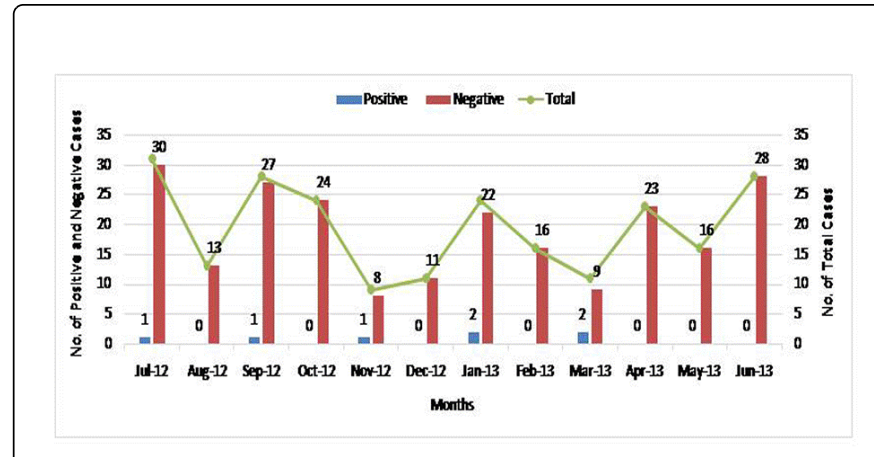

Figure 3: Month wise positivity of bocavirus.

Month wise distribution of Human bocavirus cases: $\mathrm{X}$-axis indicates months of sample collection from July 2012 to June 2013. Y-axis indicates total number of positive and negative cases and the secondary axis shows the total number of samples. Values on the blue and red bars indicate number of positive and negative samples respectively.

All the positive samples had gastrointestinal findings having diarrhea $100 \%$, dehydration $86 \%$, vomiting $70 \%$, fever $62 \%$, and severe abdominal pain $28 \%$. Age ( $\mathrm{p}=0.0486)$, duration of diarrhea in days and diarrheal frequency per day $(\mathrm{p}=0.0015, \mathrm{p}=0.0282)$ were the significant clinical features $(\mathrm{p}<0.05)$ when compared between $\mathrm{HBoV}$ positive and negative patients while there was no significant association with duration and frequency of vomiting per day (Table 2).

\begin{tabular}{|l|l|l|l|}
\hline \multicolumn{2}{|l|}{ Median (Mean \pm SD) } & & P value \\
\hline Symptoms & $\begin{array}{l}\text { HBoV } \\
\text { positive patients }\end{array}$ & $\begin{array}{l}\text { HBoV } \\
\text { negative patients }\end{array}$ & $0.0486^{*}$ \\
\hline Age & $8(24.14 \pm 27.58)$ & $34(45.19 \pm 37.69)$ & $0.0015^{*}$ \\
\hline $\begin{array}{l}\text { Duration of diarrhea } \\
\text { ( in days ) }\end{array}$ & $5(5.85 \pm 1.95)$ & $4(3.95 \pm 1.055)$ & $0.0282^{*}$ \\
\hline $\begin{array}{l}\text { Episodes of diarrhea } \\
\text { ( per day ) }\end{array}$ & $7(7 \pm 1.91)$ & $5(5.60 \pm 2.50)$ & 0.4425 \\
\hline $\begin{array}{l}\text { Duration of vomiting } \\
\text { (in days ) }\end{array}$ & $1(1.71 \pm 1.25)$ & $2(1.709 \pm 1.449)$ & 0.2393 \\
\hline $\begin{array}{l}\text { Episodes of vomiting } \\
\text { (per day ) }\end{array}$ & $3(3.28 \pm 1.79)$ & $3(2.70 \pm 2.311)$ & \\
\hline p value<0.05 considered significant and marked with asterisk & & \\
\hline
\end{tabular}

Table 2: Comparison of clinical parameters between bocavirus positive and negative patients.

\section{Phylogenetic analyses}

Human bocavirus sequences identified in this study were submitted in GenBank (Accession No. KR705903-KR705909, KR817639KR817641) and compared with the GenBank $\mathrm{HBoV}$ available bocavirus prototype strains [HBoV, NC 007455; HBoV2, NC 012042; HBoV3, NC 012564] and animal parvovirus [Canine Minute Virus,
NC 004442]. Sequence analysis showed that four $\mathrm{HBoV}$ isolates were related to $\mathrm{HBoV} 1$ and three isolates were related to $\mathrm{HBoV} 2$ species. Phylogenetic analysis of NS1 (Figure 4) and VP1/2 gene (Figure 5) shows the similarity of Indian bocavirus strain with China strains. 


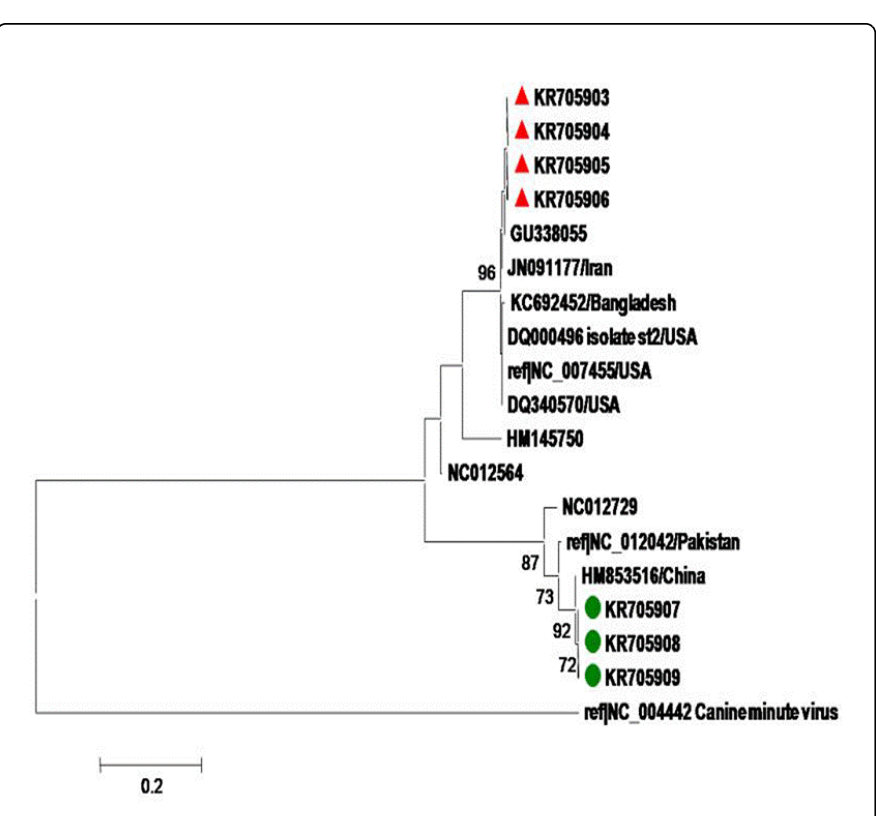

Figure 4: Phylogenetic analysis of $\mathrm{HBoV}$ sequences besed on NS1 gene sequencing.

Phylogenetic analysis of $\mathrm{HBoV}$ sequences identified in this study with sequences from other countries along with GenBank reference sequences [HBoV1, NC_007455; HBoV2, NC_012042; HBoV3, NC__012564 and Canine Minute Virus, NC_004442]. Triangles shows $\mathrm{HBoV} 1$ and circles shows HBoV2 identified in this study with their Genbank accession id. Phylogenetic analysis was done by MEGA5 (www.megasoftware.net) using maximum likelihood method; TamuraNei model and 1000 replicate bootstrapping of tree was done to obtain confidence in clade clustering.

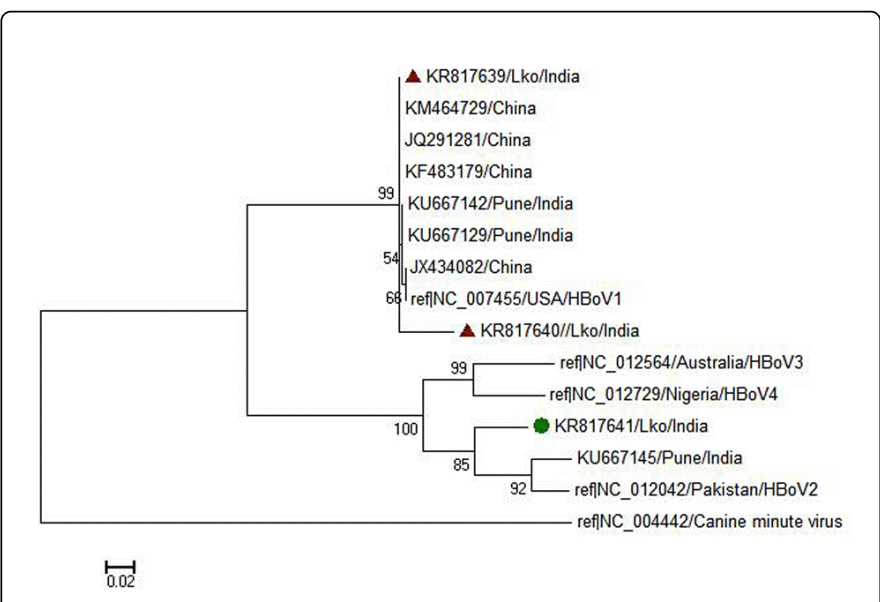

Figure 5: Phylogenetic analysis of $\mathrm{HBoV}$ sequences based on $V P 1 / 2$ gene sequencing.

Phylogenetic analysis of $\mathrm{HBoV}$ sequences identified in this study with sequences from other countries along with GenBank reference sequences [HBoV1, NC_007455; HBoV2, NC_012042; HBoV3, NC_012564 and Canine Minute Virus, NC_004442]. Triangle shows HBoV1 and circle shows HBoV2 identified in this study with their
Genbank accession id. Phylogenetic analysis was done by MEGA5 (www.megasoftware.net) using maximum likelihood method; TamuraNei model and 1000 replicate bootstrapping of tree was done to obtain confidence in clade clustering.

\section{Discussion}

Human bocavirus species are reported as common human virus infections worldwide since their first identification in 2005 [8] and 2009 [9]. The human health relevance of their infections largely remains unknown. Differences in the presence and prevalence of viruses among diseased and healthy individuals can determine the health relevance of a virus infection. $\mathrm{HBoV}$ are known to infect healthy people and are frequently detected in respiratory and enteric samples. Recent reports suggest their persistent infection in the human gastrointestinal tract [14-19]. Considering these reports, development of accurate diagnostic assays is required to identify and test the association of these viruses with diseases; therefore we aimed to obtain genetic data on $\mathrm{HBoV}$ species infecting children from north India.

This study defines the presence, prevalence and clinical association of two $\mathrm{HBoV}$ species ( $\mathrm{HBoV} 1$ and $\mathrm{HBoV} 2)$ in pediatric gastroenteritis patients. Our findings were similar to those reported by other countries indicating $\mathrm{HBoV}$ detection rate of $4-5 \%$ in stools samples of AGE cases [15]. There was no significant seasonal distribution of bocavirus in the studied period. Bocavirus infection rate was relatively higher in the month of January and March like other studies [19-21]. Age and diarrhea were main significant clinical features in bocavirus positive patients.

To best of our knowledge this is the first study to define the prevalence and association of bocavirus in gastroenteritis from North India. Phylogenetic analysis reveals the similarity of Indian bocavirus with China strains. Four bocavirus species (HBoV1-HBoV4) were recently reported by Lasure $\mathrm{N}$ [13] in gastroenteritis in Pune, West India. We were unable to detect $\mathrm{HBoV} 3$ and $\mathrm{HBoV} 4$ in gastroenteritis samples from North India. The possible explanation includes primer mismatch or genetic variation or low frequency of occurrence. Further studies are required with large sample size and year round sampling for more years. Low infection rate of $\mathrm{HBoV}$ in stool samples of children with gastroenteritis indicates that these viruses are not a common infection in the studied population.

This study has several limitations. Firstly comparatively small sample size may be a possible reason of low prevalence rate. Since bocavirus is known to present in respiratory as well as in subjects with or without gastroenteritis the most important limitation of the study was lack of an asymptomatic control group, though the presence of bocavirus in gastroenteritis sample suggests association of these viruses with AGE.

This study supports the identification and characterization of unknown etiological agents i.e. about $30 \%$ to $50 \%$ of viral gastroenteritis. The presence and prevalence of bocavirus contribute in some part of undiagnosed etiologies.

\section{Conclusion}

This study confirms the circulation of two bocavirus species (HBoV1 and HBoV2) in North India, which are genetically similar to $\mathrm{HBoV}$ genotypes, found in China. To the best of our knowledge it is the first report of the presence of $\mathrm{HBoV}$ in stool samples from North India. Genetic analysis of data generated from $\mathrm{HBoV}$ variants indicates 
endemic nature of these virus infections that cannot be discriminated based on their region of isolation. Our results will facilitate more detailed studies of HBoV infection, prevalence and disease association in Indian population.

\section{Acknowledgment}

This study is supported by fellowship grant to Richa Kapoor from Indian Council of Medical Research, New Delhi, India (grant no Ref. No: 80/734/2012-ECD-I).

\section{Ethical Approval}

This study was approved by the Institutional Ethics Committee (A-15:PGI/BE/350/7.5.2012) of, Sanjay Gandhi Post Graduate Institute of Medical Sciences, Lucknow, UP, India. Written informed consent was received from the parent or guardian of the patients.

\section{References}

1. Monica B, Ramani S, Banerjee I, Gray JJ, Kang G, et al. (2007) Human caliciviruses in symptomatic and asymptomatic infections in children in Vellore, South India. J Med Virol 79: 544-551.

2. Pativada M, Nataraju SM, Ganesh B, Rajendran K, Ramamurthy T, et al (2002) Emerging trends in the epidemiology of human astrovirus infection among infants, children and adults hospitalized with acute watery diarrhea in Kolkata, India. Infect Genet Evol 12: 1685-1693.

3. Tatte VS, Chothe NS, Chitambar SD (2014) Characterisation of rotavirus strains identified in adolescents and adults with acute gastroenteritis highlights circulation of non-typeable strains: 2008-2012. Vaccine 32: A68-A74.

4. Simpson R, Aliyu S, Iturriza-Gómara M, Desselberger U, Gray J 2003) Infantile viral gastroenteritis: On the way to closing the diagnostic gap. J Med Virol 70: 258-262.

5. Olesen B, Neimann J, Böttiger B, Ethelberg S, Schiellerup P, et al. (2005) Etiology of diarrhea in young children in denmark: A case-control study. J ClinMicrobiol 43: 3636-3641.

6. Jones MS, Kapoor A, Lukashov VV, Simmonds P, Delwart E, et al. (2005) New DNA viruses identified in patients with acute viral infection syndrome. J Virol 79: 8230-8236.

7. Fryer JF, Kapoor A, Minor PD, Delwart E, Baylis SA (2006) Novel parvovirus and related variant in human plasma. Emerg Infect Dis 12: 151.
8. Allander T, Tammi MT, Eriksson M, Bjerkner A, Andersson B, et al. (2005) Cloning of a human parvovirus by molecular screening of respiratory tract samples. Proc Natl Acad Sci USA 102: 12891-12896.

9. Kapoor A, Slikas E, Simmonds P, Chieochansin T, Naeem A, et al. (2009) A newly identified bocavirus species in human stool. J Infect Diseas 199: 196-200.

10. Arthur JL, Higgins GD, Davidson GP, Givney RC, Ratcliff RM (2009) A novel bocavirus associated with acute gastroenteritis in australian children. PLoS pathogens 5: e1000391.

11. Kapoor A, Simmonds P, Slikas E, Li L, Bodhidatta L, et al. (2010) Human bocaviruses are highly diverse, dispersed, recombination prone, and prevalent in enteric infections. J Infect Diseas 201: 1633-1643.

12. Bharaj P, Sullender WM, Kabra SK, Broor S (2010) Human bocavirus infection in children with acute respiratory tract infection in india. J Med Virol 82: 812-816.

13. Lasure N, Gopalkrishna V (2016) Molecular epidemiology and clinical severity of human bocavirus (hbov) 1-4 in children with acute gastroenteritis from pune, western india . J Med Virol.

14. Kapoor A, Mehta N, Esper F, Poljsak-Prijatelj M, Quan PL, et al. (2010) Identification and characterization of a new bocavirus species in gorillas. PLoS One 5: el1948.

15. Yu JM, Li DD, Xu ZQ, Cheng WX, Zhang Q, et al. (2008) Human bocavirus infection in children hospitalized with acute gastroenteritis in china. J ClinVirol 42: 280-285.

16. Campe H, Hartberger C, Sing A (2008) Role of human bocavirus infections in outbreaks of gastroenteritis. J Clinl Virol 43: 340-342.

17. Lee JI, Chung JY, Han TH, Song MO, Hwang ES (2007) Detection of human bocavirus in children hospitalized because of acute gastroenteritis. J Infect Dis 196: 994-997.

18. Albuquerque MCM, Rocha LN, Benati FJ, Soares CC, Maranhão AG, et al. (2007) Human bocavirus infection in children with gastroenteritis, Brazil. Emerg Infect Dis 13: 1756.

19. Schildgen O, Müller A, Simon A (2007) Human bocavirus and gastroenteritis. Emerg Infect Dis 13: 1620.

20. Lau SK, Yip CC, Que Tl, Lee RA, Au-Yeung RK, et al. (2007) Clinical and molecular epidemiology of human bocavirus in respiratory and fecal samples from children in hong kong. JInfectDis 196: 986-993.

21. Manning A, Russell V, Eastick K, Leadbetter G, Hallam N, et al. (2006) Epidemiological profile and clinical associations of human bocavirus and other human parvoviruses. J InfectDis 194: 1283-1290.

22. Foulongne V, Olejnik Y, Perez V, Elaerts S, Rodière M, et al. (2006) Human bocavirus in french children. Emerg infect dis 12: 1251-1253. 